\title{
$\bar{G}$
}

DOI: 10.1515/plass-2017-0002

Agnieszka Hara-Skrzypiec

Plant Breeding and Acclimatization Institute - National Research Institute Młochów Research Center, 05-831 Młochów, Platanowa Str. 19, Poland e-mail: a.hara@ihar.edu.pl

\section{EVALUATION OF TENDENCY TO BLACKSPOT BRUISING AND ENZYMATIC DISCOLORATION OF POTATO TUBERS}

\begin{abstract}
Enzymatic discoloration of potato tubers initiated by mechanical impact bruising and the discoloration which appears after tuber cutting are crucial quality traits of the cultivated potato. The presented determination of blackspot bruise susceptibility includes evaluation of the trait with two impact methods - the rotating drum and the falling bolt. These two methods affect both the physical and the biochemical properties of tubers. Evaluation of the discoloration potential after tuber cutting (ED) is also discussed. Evaluating the discoloration potential of tubers is one of the most important points in determining potato quality.
\end{abstract}

Key words: bolt method, mechanical damage, rotating drum method, tuber flesh darkening falling

\section{INTRODUCTION}

Blackspot bruising and enzymatic discoloration are undesired discolorations affecting the quality of potato tubers. In enzymatic discoloration, dark pigments appear after peeling and cutting the tuber. The formation of blackspot bruises is initiated by mechanical impact. Bruising can occur during harvest and at all stages of postharvest handling. Blackspots typically occur 1-3 days after tuber impact and are seen only after the removal of the tuber skin. When cells are damaged, polyphenol oxidase (PPO) and phenols, normally separated by cellular compartmentation, come into contact. A series of oxidative reactions of phenols, primarily tyrosine, result in the formation of melanins (Cobb, 1999). Bruising leads to rejection of the crop by consumers and the processing industry, thus resulting in considerable economic losses (Storey, 2007). The formation of discolorations depends on multiple

Communicated by Ewa Zimnoch-Guzowska 
factors: the genotype, the environment as well as the anatomical, physical and physiological properties of tuber tissues such as starch content (McGarry et al., 1996; Urbany et al., 2011). So far, various methods in evaluation of blackspot bruise tendency have been used: abrasive tests, drop weight tests, the pendulum, shaking tables, rotating drums (Dean et al., 1993; Urbany et al., 2011; Hara-Skrzypiec and Jakuczun, 2013; Hara-Skrzypiec et al., 2017). At IHAR-PIB Młochów, diploid Solanum hybrids with a low tendency for bruising were selected (Hara-Skrzypiec and Jakuczun, 2013) by means of two evaluation methods: the drum test and the falling bolt method. Owing to the complexity of the trait and the significant effects of the year and the genotype $\mathrm{x}$ year interaction in determining traits shown in studies (McGarry et al.1996; Hara-Skrzypiec and Jakuczun, 2013; Hara-Skrzypiec et al., 2017), evaluation of traits should be conducted in multi-replicates and 2-3 year trials. Due to physiological aging, turgor and membrane permeability changes throughout the shelf life, therefore evaluating susceptibility to bruising sometime after harvest is more reliable than immediately after harvest.

\section{EVALUATION OF BLACKSPOT BRUISE SUSCEPTIBILITY USING ROTATING DRUM METHOD}

\section{Materials}

Potato tubers

\section{Equipment}

A hexagonal drum (Douches et al., 2003), (Photo1).

\section{Procedure}

1) 14 to 20 undamaged, non-greening tubers uniform in size are selected in each of 2-3 replicates.

2) The sample tubers are stored at $5^{\circ} \mathrm{C}$ to $10^{\circ} \mathrm{C}$ for 5 months.

3) Then, the tubers are stored at $11^{\circ} \mathrm{C}$ for $12 \mathrm{~h}$ and placed in a hexagonal drum that is rotated ten times to stimulate formation of blackspots.

4) After testing, the bruised tubers are stored at $20^{\circ} \mathrm{C}$ for $72 \mathrm{~h}$.

5) After peeling the tubers, the mean surface of blackspot bruises is visually evaluated and the tubers are divided into four quality groups: $\mathrm{A}=0$ $25 \%$ of the tuber surface covered by bruises, non-existent or weak bruising; $\mathrm{B}=25-50 \%$ of the tuber surface covered by bruises, medium bruising; $\mathrm{C}=50-75 \%$ of the tuber surface covered by bruises, strong bruising; and $\mathrm{D}=75-100 \%$ of the tuber surface covered by bruises, very strong bruising (Photo 2).

6) A bruising index (BI) is calculated with the formula:

$$
B I=\frac{(0.25 \times A+0.5 \times B+0.75 \times C+D)}{N_{t t}} \times 100
$$


(a modified method according to Urbany et al., 2011), where $N_{t t}$ number of tested tubers.

The $B I$ ranges from 0 (resistant to blackspot bruising) to 100 (the most susceptible to bruising).

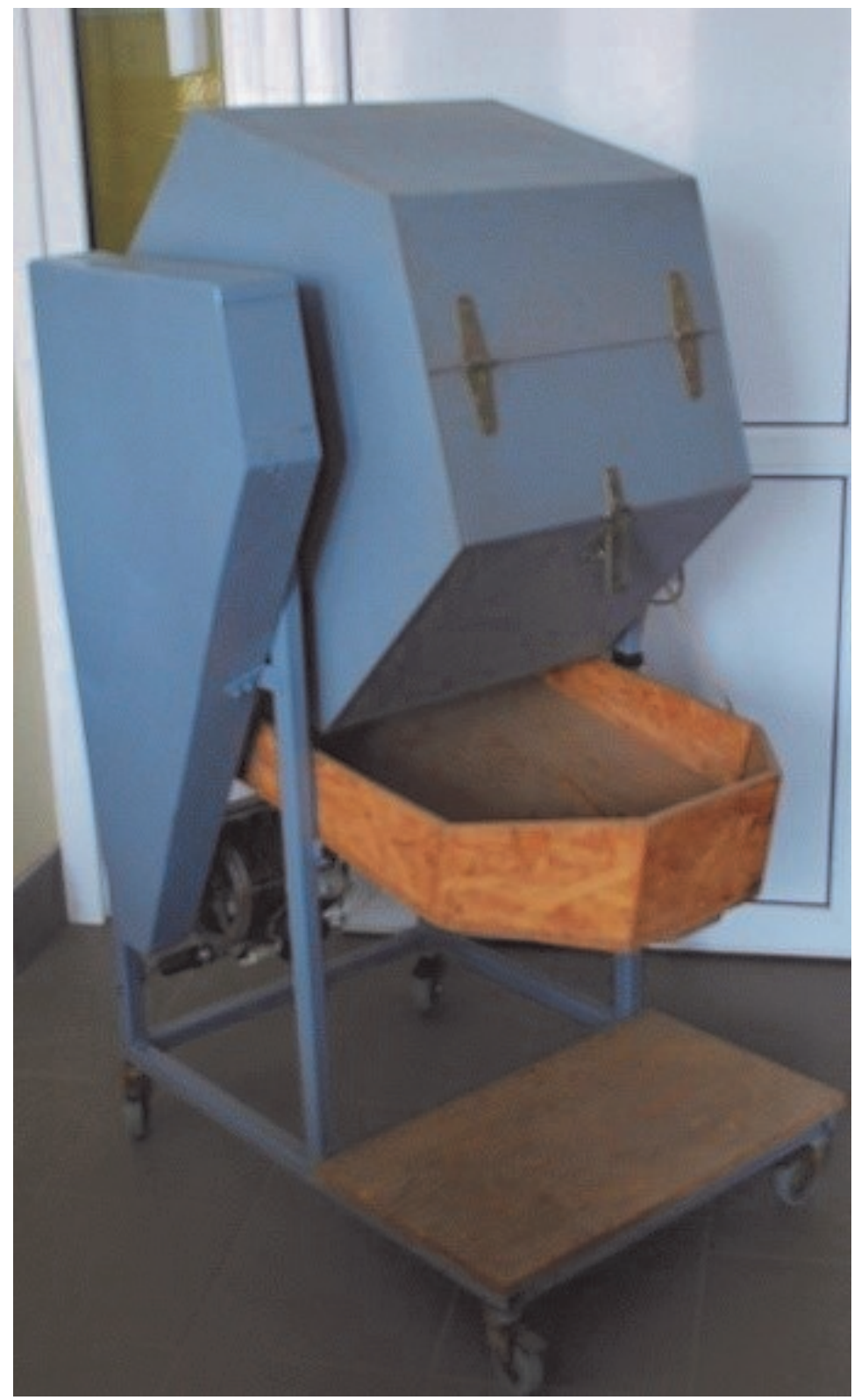

Photo 1. A hexagonal drum used to simulate the formation of blackspots 

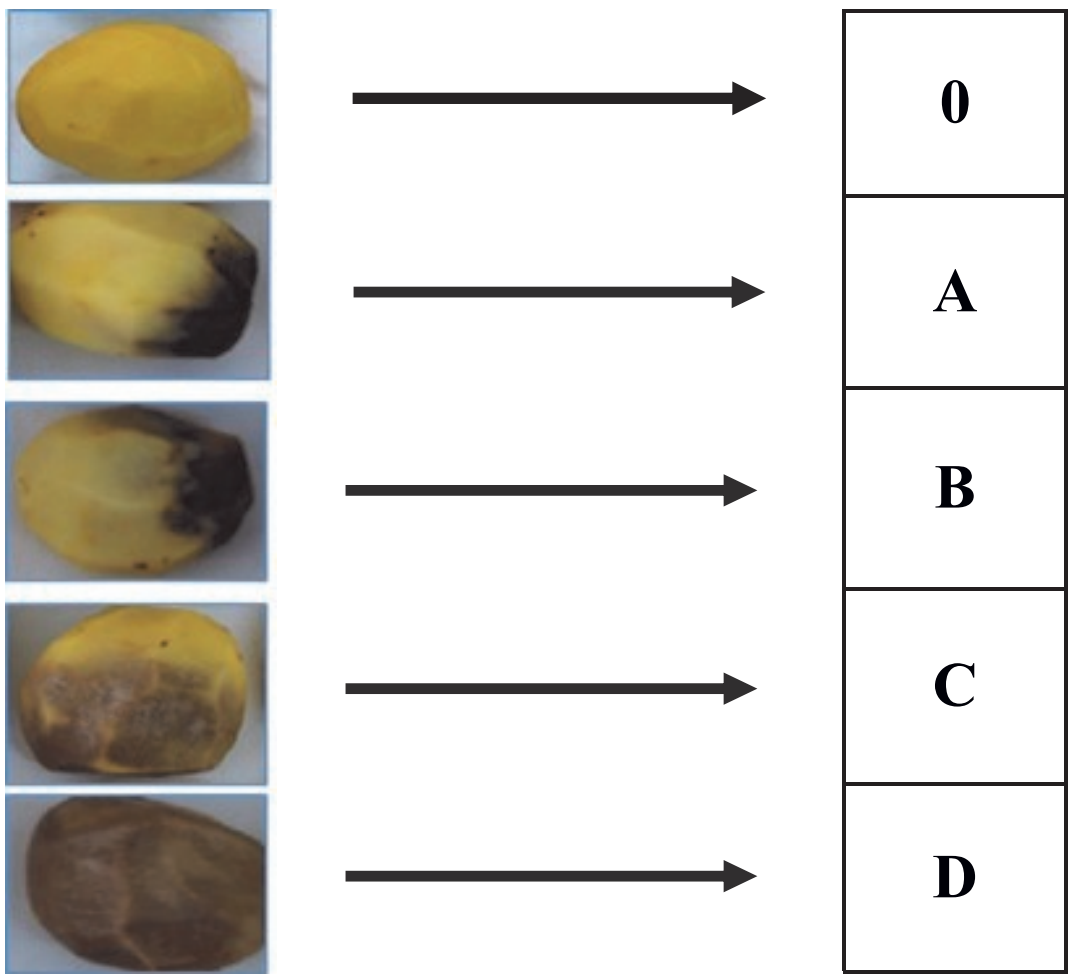

Photo 2. Evaluation scale of blackspot bruise susceptibility using rotating drum method

\section{USING FALLING BOLT METHOD}

\section{Materials}

Potato tubers

\section{Equipment}

A metal bolt imparting $0.76 \mathrm{~J}$ of energy (Photo 3A).

\section{Procedure}

1) 5 undamaged, non-greening and uniform in size tubers are selected in each of 2-3 replicates.

2) Tubers are stored for 5 months at $5^{\circ} \mathrm{C}$ to $10^{\circ} \mathrm{C}$.

3) After incubation at $11^{\circ} \mathrm{C}$ for $12 \mathrm{~h}$, the tubers were inflicted once close to stolon scar by a metal bolt.

4) After testing, the bruised tubers are stored at $20^{\circ} \mathrm{C}$ for $72 \mathrm{~h}$. 
5) Each tested tuber was transected through the site of mechanical impact (Photo 3B). The spot sizes (diameter and depth in $\mathrm{mm}$ ) and colour intensity of the bruises were rated according to a 1-5 scale of Hironaka et al. (1996): $0=$ no discoloration, 1 = very small spots or vaguely defined; $2=$ diameter 3 to $5 \mathrm{~mm}$, depth less than $5 \mathrm{~mm}$ colour grey or brownish; $3=$ diameter 5 to $10 \mathrm{~mm}$, depth less than $5 \mathrm{~mm}$, colour grey or black; $4=$ diameter 5 to 10 $\mathrm{mm}$, depth greater than $5 \mathrm{~mm}$, colour grey or black and $5=$ diameter greater than $10 \mathrm{~mm}$, depth greater than $5 \mathrm{~mm}$, colour black.

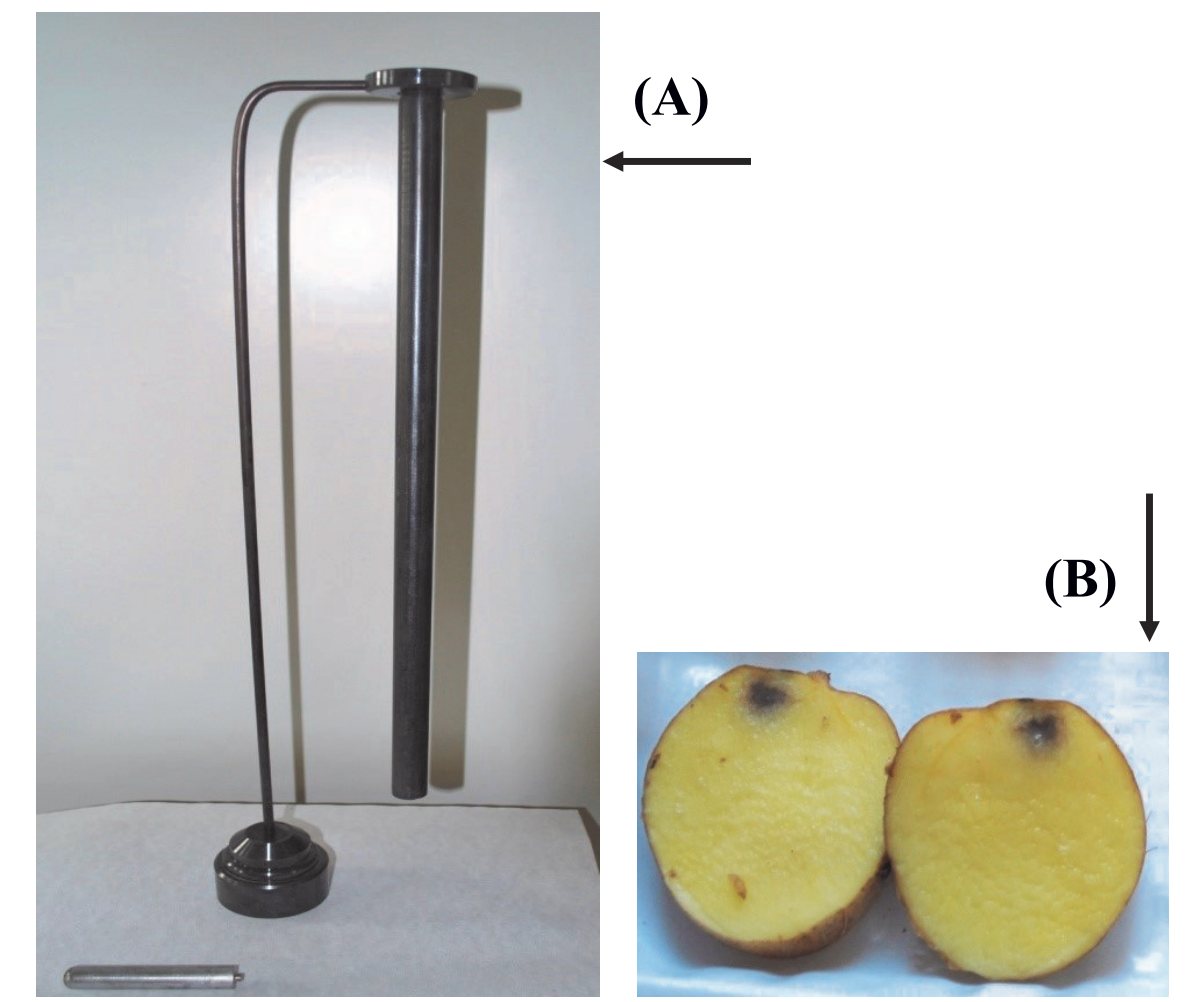

Photo 3. A falling bolt used in evaluation of blackspot bruise susceptibility (A) and tuber transected for mechanical damage evaluation (B)

EVALUATION OF ENZYMATIC DISCOLORATION OF RAW POTATO TUBERS (ED)

\section{Materials}

Potato tubers

\section{Equipment}

A colour chart for determining the discoloration of the potato (Dansk Gærings- Industri, Ltd, Copenhagen, Denmark) 


\section{Procedure}

1) Five, undamaged tubers after 3-month storage are selected in each of 23 replicates. The standards are presented by two control cultivars: with a low (e.g. cv. Vineta) and a high (e.g. cv. Hinga) tendency for ED of raw tuber flesh.

2) The degree of ED is evaluated $4 \mathrm{~h}$ after the tuber has been cut in half.

3) The level of ED is scored according to a colour chart for determining the discoloration of the potato on a scale of 1 to 9 (where $1=$ the strongest discoloration, and $9=$ a lack of discoloration).

\section{ACKNOWLEDGMENTS:}

Elaboration of the methods of the blackspot bruise susceptibility assessment was partially supported by The National Science Centre in Poland, Grant UMO2012/05/N/NZ9/01295.

\section{REFERENCES}

Cobb A.H. 1999. A review of the physiology of bruising in potatoes. The 14th Triennial Conference of the European Association for Potato Research, Sorrento, Italy: 198-199.

Dean B.B., Jackowiak N., Nagle M., Pavek J., Corsini D. 1993. Blackspot pigment development of resistant and susceptible Solanum tuberosum L. genotypes at harvest and during storage measured by three methods of evaluation. Am. Potato J. 70: 201-217.

Douches D.D., Chase R.W., Coombs J., Flecher K., Frank L., Driscoll J., Estellee E., Hammerschmidt R., Kirk W. 2003. Seventy-second annual report by Michigan State University In: National Germplasm Evaluation and Enhancement Report, 2001. Ed. By K.G. Haynes. Seventy Second Annual Report by Cooperators. US Department of Agriculture Agricultural Research Service, ARS-162: 171 - 199.

Hara-Skrzypiec A., Jakuczun H. 2013. Diploid potato hybrids as sources of resistance to blackspot bruising. Am. J Potato Res. 90: 451-459.

Hironaka K., Ishibashi K-I., Ono K. 1996. Change in bruise susceptibility of potatoes during storage. Research Bulletin of Obihiro University 20: 35-39.

McGarry A., Hole C.C., Drew R.L.K., Parsons N. 1996. Internal damage in potato tubers: a critical review. Postharvest Biol Tec 8: 239-258.

Storey R.M.J. 2007. The harvested crop. In: Potato Biology and Biotechnology: Advances and Perspectives, ed. Vreugdenhil D. et al. Amsterdam, The Netherlands: Elsevier, 459-468.

Urbany C., Stich B., Schmidt L., Simon L., Berding H., Junghans K., Niehoff K-H., Braun A., Eckhard T., Hofferbert H-R., Lübeck J., Strahwald J., Gebhardt C. 2011a. Association genetics in Solanum tuberosum provides new insights into potato tuber bruising and enzymatic tissue discoloration. BMC Genomics 12: 7 